\title{
Effect of liquid-forming additives on low-temperature superplastic deformation of alumina
}

L. A. XUE

Department of Materials Science and Engineering, The University of Michigan, Ann Arbor, MI 48109, USA

It has recently been reported that in the $\mathrm{Y}_{2} \mathrm{O}_{3}$-stabilized tetragonal zirconia phase (TZP) system the addition of a small amount of transition-metal oxides (e.g. $\mathrm{CuO}, \mathrm{MnO}$ and $\mathrm{ZnO}$ ) which form a liquid or amorphous grain boundary phase significantly enhances superplasticity $[1,2]$. In $\mathrm{CuO}$-added $2 \mathrm{Y}$-TZP abrupt changes have been found in the stress exponent and activation energy across the melting temperature, which are consistent with the proposed deformation mechanism that the superplasticity in these cases is diffusion-controlled below the melting temperature and is interface-controlled above that [1]. Similar deformation characteristics have also been observed in an $80 \mathrm{wt} \% 2 \mathrm{Y}-\mathrm{TZP} / \mathrm{Al}_{2} \mathrm{O}_{3}$ composite doped with liquid-forming additives [3].

The deformation of transition-metals-doped alumina has been studied before [4-10]. Due to the coarse-grained (usually of the order of $10 \mu \mathrm{m}$ ) samples used in these studies, deoformation has always been conducted in the creep range with strain rates $<10^{-5} \mathrm{~s}^{-1}$ and to small strains. Creep enhancement by the dopants has generally been observed, especially in alumina simultaneously doped with compensating dopants, e.g. $\mathrm{Ti}^{4+}+\mathrm{Cu}^{2+}[4], \mathrm{Ti}^{4+}$ $+\mathrm{Fe}^{2+}[5]$ and $\mathrm{Ti}^{4+}+\mathrm{Mn}^{2+}$ [6]. The influence of the transition-metal additives in these studies has been interpreted in terms of defect chemistry [10], although liquid phases may be present in systems doped with $\mathrm{Ti}^{4+}+\mathrm{Cu}^{2+}$ [4]. We have recently shown that, when doped with 2 mol \% liquid-forming additives containing compensating dopants, a commercial alumina powder can be sintered to a dense ultrafine-grained $(0.3 \mu \mathrm{m})$ ceramic at a temperature as low as $1070^{\circ} \mathrm{C}$ [11]. Such a fine-grained microstructure should enable us to conduct the deformation study in the superplastic flow region at relatively low temperatures. In this letter we report the superplastic deformation behaviour of low-temperature sintered alumina doped with 2 mol\% liquid-forming additives which shows a greatly enhanced superplasticity and a similar temperaturedependent characteristic to that found in $\mathrm{CuO}$ added $2 Y-T Z P$.

A commercial high-purity $(>99.99 \%)$ alumina powder (TM-D, Taimei Chemicals, Tokyo, Japan) was used as the starting material, which was subsequently doped with a liquid-forming additive $\left(0.9 \mathrm{~mol} \% \quad \mathrm{TiO}_{2}+0.9 \mathrm{~mol} \% \quad \mathrm{CuO}+0.1 \mathrm{~mol} \%\right.$ $\left.\mathrm{B}_{2} \mathrm{O}_{3}+0.1 \mathrm{~mol} \% \mathrm{MgO}\right)$. Details of the material preparation were described in [11]. Specimens with densities greater than $98.5 \%$ theoretical (which was achieved by sintering at $1070{ }^{\circ} \mathrm{C}$ for $1 \mathrm{~h}$ ) were used in the deformation study. Specimens for testing were cut from sintered samples into square bars of aspect ratio 2.2. Deformation was conducted in uniaxial compression in air, between 950 and $1200^{\circ} \mathrm{C}$, with strain rates from $3 \times 10^{-6}$ to $5 \times 10^{-3} \mathrm{~s}^{-1}$. Other experimental details were similar to those reported in [1].

The as-sintered doped alumina features an ultrafine microstructure with an average grain size of $0.3 \mu \mathrm{m}$, as can be seen from Fig. 1a. As discussed previously [11], abnormal elongated grain growth
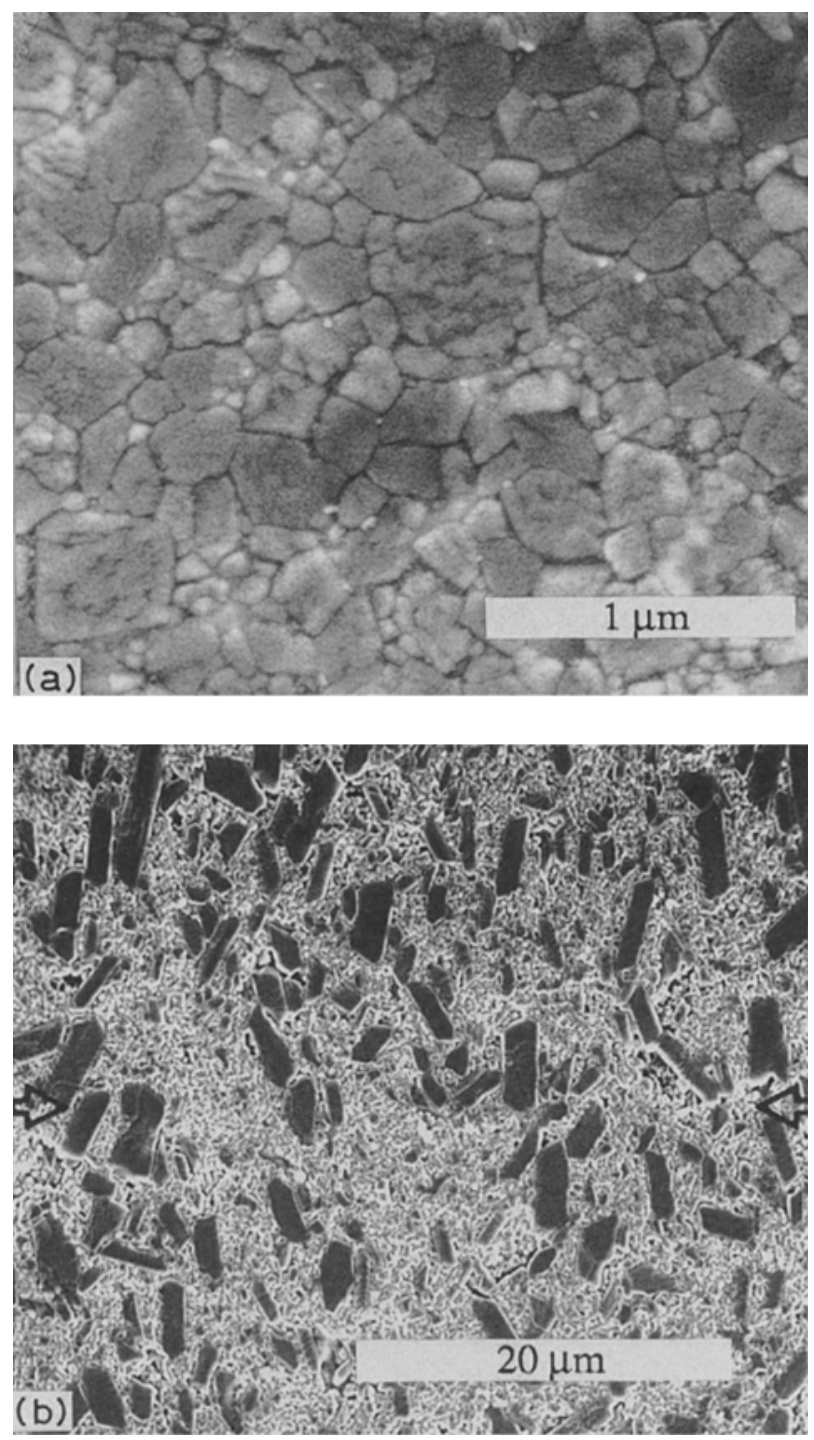

Figure 1 Scanning electron micrographs of alumina doped with $2 \mathrm{~mol} \%$ liquid-forming additives: (a) before deformation and (b) after deformation at $1200{ }^{\circ} \mathrm{C}$ to a true stain of -0.6 . The compression axis is indicated by the hollow arrows. 
occurred during sintering at higher temperatures or for a prolonged sintering time. This kind of abnormal grain growth also developed during the deformation, which was especially pronounced at temperatures higher than $1100^{\circ} \mathrm{C}$. Fig. $1 \mathrm{~b}$ shows the microstructure of a sample deformed at $1200^{\circ} \mathrm{C}$ and at a strain rate of $2.4 \times 10^{-3} \mathrm{~s}^{-1}$ to a true strain of -0.6 , showing predominant abnormal grain growth. At low strain levels (about 0.05) at which the stress-strain rate data were taken, however, the volume fraction of these larger elongated grains was small, being $<10 \%$. According to Chen's continuum model for composites [12], this "inclusion phase" (i.e. these abnormal grains) would not alter the overall flow stress in any significant ways. The existence of these large abnormal grains does, nevertheless, introduce local stress concentrations and therefore cause cavitation at high strain rates even under compression. As a result, the obtainable tensile strain of this material has been found to be rather low, being only about $15 \%$. In view of this, the tensile superplasticity of this doped alumina seems to be limited owing to the occurrence of the abnormal grain growth.

It is interesting to observe from Fig. $1 \mathrm{~b}$ that during deformation these elongated grains align preferentially along the direction perpendicular to the compression axis. This preferred orientation has been found to be deformation strain-dependent; specimens deformed at the same temperature and strain rate, but to different strains, show that the higher the strain is, the higher the degree of the alignment. The phenomenon may be employed in the future as a viable technique to achieve preferred orientation of fibre/whisker in ceramic composites.

The superplastic flow behaviour of the doped alumina is summarized in Fig. 2. For comparison, the flow stress-strain rate relation at $1250{ }^{\circ} \mathrm{C}$ of a pure alumina with an average grain size of $0.5 \mu \mathrm{m}$ is also shown [13]. It is obvious that the additive greatly enhances the superplasticity of alumina; it

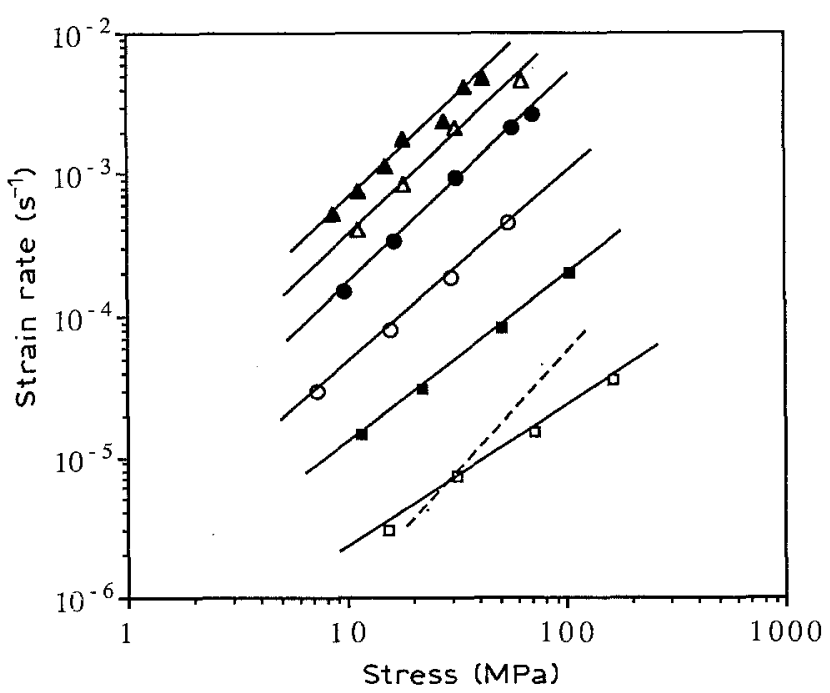

Figure 2 Flow stress-strain rate relationships for the doped

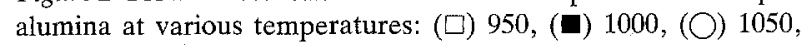
(十) $1100,(\triangle) 1150$ and $(\Delta) 1200^{\circ} \mathrm{C}$. The broken line is for a pure fine-grained $(0.5 \mu \mathrm{m})$ alumina at $1250^{\circ} \mathrm{C}[13]$. lowers the deformation temperature by $300^{\circ} \mathrm{C}$, or (when extrapolating the $1250^{\circ} \mathrm{C}$ pure alumina data to $1200{ }^{\circ} \mathrm{C}$ ) increases the strain rate by four orders of magnitude. The apparent melting temperature for the liquid phase in this system seems to be in the range $1050-1100^{\circ} \mathrm{C}$, which is in agreement with the differential thermal analysis finding that shows the onset of an endothermic peak at approximately $1040{ }^{\circ} \mathrm{C}$ [11], but a significant deformation enhancement has already been found at a temperature as low as $950^{\circ} \mathrm{C}$. A similar observation has been made in the CuO-added 2Y-TZP system [1]. The degree of the enhancement by the dopants is in good agreement with that found $\left(10^{4}\right)$ by Cannon [4] for alumina doped with $2 \mathrm{~mol} \% \mathrm{Ti}+2 \mathrm{~mol} \% \mathrm{Cu}$ at $1200{ }^{\circ} \mathrm{C}$ in the creep range.

It can be noted from Fig. 2 that the slopes of these stress-strain rate data for the doped alumina, which are near unity at $950^{\circ} \mathrm{C}$, become steeper at higher temperatures. In all cases the slopes are less steep than that for the pure alumina. The change in the slope means that the stress exponent, $n$, increases with the temperature. As highlighted in Fig. 3, the value of $n$ increases gradually as the temperature increases, then goes through a somewhat abrupt transition at a temperature around $1100{ }^{\circ} \mathrm{C}$. The $n$-value (between 1 and 1.5) found in the present study is relatively low compared with that for pure alumina (about 1.7), and is characteristic of superplastic flow.

The temperature dependence of the superplastic flow undergoes a corresponding transition, becoming lower at higher temperatures (Fig. 4). The activation energy at lower temperatures (457 $\mathrm{kJ} \mathrm{mol}^{-1}$ ), which is comparable with that of pure alumina $\left(460 \mathrm{~kJ} \mathrm{~mol}^{-1}\right.$ [13]) decreases quickly to $243 \mathrm{~kJ} \mathrm{~mol}^{-1}$ at higher temperatures.

The transition in superplastic flow behaviour in the vicinity of the melting temperature of the liquid phases, i.e. increase in stress exponent and decrease in activation energy, has been identified in the CuO-doped 2Y-TZP system as the consequence of the grain boundary liquid phase formed [1]. The

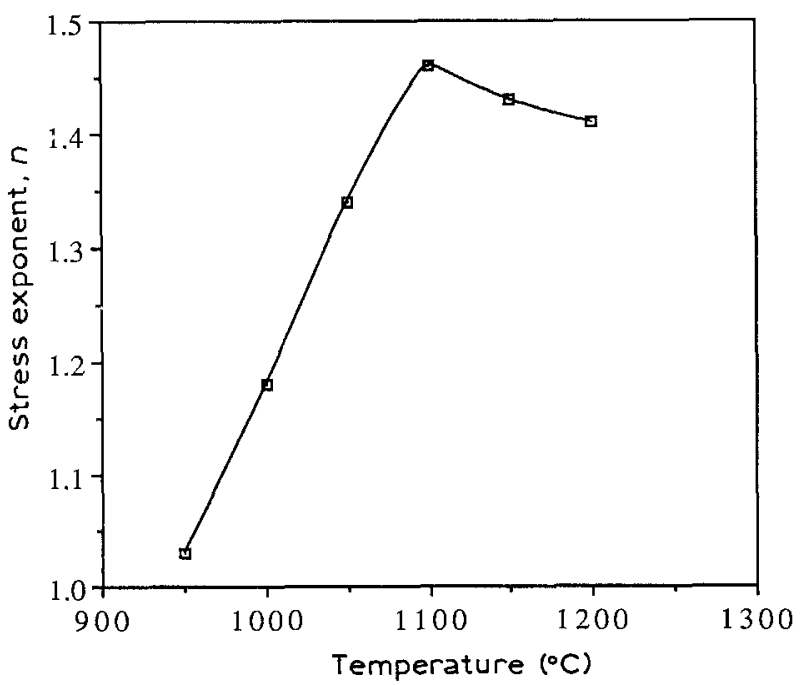

Figure 3 Temperature dependence of the stress exponent, $n$, for the doped alumina. 


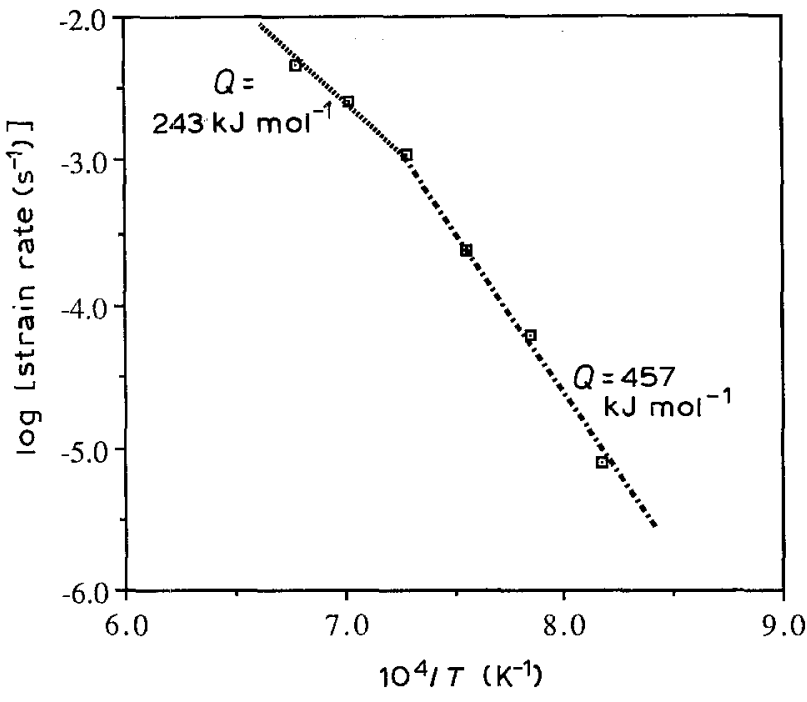

Figure 4 Temperature dependence of strain rate for the doped alumina at $40 \mathrm{MPa}$. The values of the activation energy, $Q$ are indicated for the two temperature ranges,

deformation mechanism there, which was dominated by a grain boundary phase-enhanced diffusion below the eutectic temperature, shifted to a liquidenhanced interface-controlled one at higher temperatures [1]. The close similarities in the deformation characteristics between the $\mathrm{CuO}$-doped $2 \mathrm{Y}$ TZP and the doped alumina in the present study tends to suggest that these two deformation mechanisms are also operative in the latter system.

To summarize, $2 \mathrm{~mol} \%$ liquid-forming additives containing compensating dopants enhances the deformation rate of alumina by four orders of magnitude. At low strain rates or high temperatures, elongated abnormal grain growth occurs during the superplastic deformation, which gives rise to cavitation at large strains and hence becomes the cause of rather limited tensile strain (about 15\%) for the material. There are abrupt changes in the stress exponent and activation energy across the apparent melting temperature of the liquid phase, suggestive of a shift of the deformation mechanism from diffusion control below the melting temperature to interface control above that.

\section{Acknowledgement}

This research was supported by the US National Science Foundation under Grant No. DDM-9024975.

\section{References}

1. C. - M. J. HWANG and I. -W. CHEN, J. Amer. Ceram. Soc. 73 (1990) 1626

2. I. - W. CHEN and L. A. XUE, ibid. 73 (1990) 2585.

3. L. A. XUE, J. Mater. Sci. Lett. 11 (1992) 1395.

4. W. R. CANNON, in "Advances in ceramic", Vol. 10: "Structure and properties of $\mathrm{MgO}$ and $\mathrm{Al}_{2} \mathrm{O}_{3}$ ceramics", edited by W. D. Kingery (American Ceramic Society, Columbus, Ohio, 1984) p. 741.

5. Y. IKUMA and R.S. GORDON, J.Amer. Ceram. Soc. 66 (1983) 139

6. Idem, J. Mater. Sci. 17 (1982) 2961

7. P. A. LESSING and R. S. GORDON, ibid. 12 (1977) 2291.

8. A. CROSBY and P. E. EVANS, ibid. 8 (1973) 1573.

9. G. W. HOLLENBERG and R. S. GORDON, J. Amer Ceram. Soc. 56 (1973) 140.

10. R. S. GORDON, in "Advances in ceramics", Vol. 10: "Structure and properties of $\mathrm{MgO}$ and $\mathrm{Al}_{2} \mathrm{O}_{3}$ ceramics", edited by. W. D. Kingery (American Ceramic Society, Columbus, Ohio, 1984) p. 418.

11. L. A. XUE and I.-W. CHEN, J. Amer. Ceram. Soc. 74 (1991) 2011.

12. I.-W. CHEN, in "Superplasticity", edited by B. Baudelet and M. Suery (Centre National de la Recherche Scientifique, Paris, 1985) p. 5.1.

13. L. A. XUE and I.-W. CHEN, J. Amer. Ceram. Soc. 73 (1990) 3518 .

Received 31 October 1991

and accepted 13 April 1992 